\title{
Blackburn's Supervenience Argument Against Moral Realism: Revisited
}

In his famous argument Blackburn (1970/923), 1984, 1985/93) tries to show the untenability of moral realism, specifically moral naturalism (or at least, its inferiority to his own quasirealism). The argument is that there is no conceptual entailment from satisfying a naturalistic predicate, however complex, to satisfying a moral predicate; no a priori knowable route from the first to the second. But it is a priori knowable that two subjects of predication cannot differ morally without differing naturalistically; the moral is conceptually supervenient on the natural. However, this bare conceptual supervenience of the moral on the natural (the conjunction of conceptual supervenience with lack of conceptual entailment), is something the non-realist can explain, but the realist cannot.

I argue for two theses. The first is that Blackburn's best formulation of his challenge is his first one. ${ }^{1}$ Subsequently he reformulates it as a demand for the realist to explain a 'ban on mixed worlds'. Many critics have directed their arguments against this formulation but they are ineffective against Blackburn's first formulation of the challenge, as briefly set out above. Nonetheless, my second thesis is, even when it is so formulated the realist can meet the challenge. The bare conceptual supervenience of the moral on the natural can be given a realist explanation. This can be done by understanding names of moral properties as descriptive names (in the sense of Evans 1979) of natural properties. ${ }^{2}$

\footnotetext{
${ }^{1}$ Strictly speaking it is not necessary for Blackburn to present the general thesis of the bare conceptual thesis of the moral on the natural as the explanandum in his challenge. He can simply take an instance of the thesis, with a particular moral predicate, e.g., 'is a virtuous character trait', and demand the realist explain the instance. All he needs to claim victory is one explanatory failure from his opponent.

${ }^{2}$ To avoid the supervenience thesis being a triviality, natural properties must be understood to be multiply instantiable. But this leaves a lot of scope. Predicates expressing them can still refer to spatiotemporal locations. It is not a priori that two things cannot have the same origin, or even be at all times coincident (these are matters of philosophical dispute). Natural properties can also be relational, and the class for our purposes includes psychological properties. It also includes such complex relational-cum-psychological properties as being
} frightening to women. In addition the specification of a natural property can require reference 
There are (at least) four ways the realist can try to meet Blackburn's challenge. First, he might try to deny the bare conceptual supervenience claimed by denying the lack of conceptual entailment. Secondly, he might concede it but say that it does not ensure the metaphysical possibility of two worlds alike in all natural respects but differing morally. In other words, he might say that there is not only, what Blackburn insists upon, metaphysical intraworld supervenience, but also metaphysical interworld supervenience, which Blackburn is required to deny. Thirdly, he might argue that the non-realist is no more capable of explaining bare conceptual convenience than he is. Fourthly, he might accept that everything Blackburn says in his original paper is true, embrace Blackburn's bare supervenience thesis as correct, but offer a realist explanation of it.

In what follows I will be discussing only the second and fourth realist responses. My first thesis, argued for in this section, is that the second response fails by targeting an inferior formulation of Blackburn's challenge. My second thesis is that the fourth response can be implemented successfully.

The second realist response is probably the most popular in the literature. ${ }^{3}$ What motivates it is Blackburn's subsequent restatement of his initial challenge as a demand for an explanation of the 'ban on mixed worlds'. In his initial formulation Blackburn presents his challenge as above. He does not talk of (mixed) worlds. Later, having lost his pre-Kripkean

to individuals. So the class can include such properties as being amusing to Donald Trump or being commanded by Odin or forbidden by Zeus. For the purpose of this discussion then (as Blackburn himself states) natural properties can include supernatural ones, and divine command theories of morality are a subspecies of natural ones. (Though it is, of course, a reasonable question whether someone who holds that two token actions might differ morally though the only difference between them is that one is commanded by Odin and the other forbidden by him understands moral vocabulary any better than someone who thinks that the only relevant moral difference might be that one is amusing to Trump and the other not. And if it is agreed that these differences can make no moral difference but said that being commanded by e.g., the Christian God can, then perhaps some more explanation is needed.) ${ }^{3}$ See Klagge (1984), McFetridge (1985), Shoemaker (1987), Dreir (1992), Zangwill (1995), Bloomfield (2001), Sobel (2001) and Majors (2009). 
innocence, in his book Spreading the Word (1984) and later he does. He states the bare supervenience thesis as the thesis that there is $\mathrm{B} * / \mathrm{A}$ supervenience without $\mathrm{B} * / \mathrm{A}$ necessity, where the A properties are the moral ones and $\mathrm{B}^{*}$ is a complete naturalistic specification of a thing. He thinks of $\mathrm{B}^{*} / \mathrm{A}$ supervenience as an intraworld affair and thinks that the lack of $\mathrm{B} * / \mathrm{A}$ necessity means that there are metaphysically possible worlds in which $\mathrm{B} *$ things are A and worlds in which $\mathrm{B}^{*}$ things are not $\mathrm{A}$. What is ruled out by $\mathrm{B} * / \mathrm{A}$ supervenience is just 'mixed worlds', ones in which some things that are $\mathrm{B}^{*}$ are $\mathrm{A}$ and some things that are $\mathrm{B}^{*}$ are not A. But, he argues, the moral realist cannot explain this. He 'has a concept of an actual moral state of affairs, which might or might not distribute in a particular way across the naturalistic states. Supervenience [and hence the ban on mixed worlds] thus becomes a mysterious fact, and one of which he will have no explanation (or no right to rely on). It would be as though some people are [ $\mathrm{N}$ and doing the right thing], and others are [ $\mathrm{N}$ but doing the wrong thing] but there is a ban on them travelling to the same place; completely inexplicable' (1984: 185-6).

The standard response to Blackburn, then, is simply that there is interworld supervenience as well as intraworld supervenience, so it is not the case that all that are ruled out are mixed worlds. As Shoemaker (1987:440) puts it: 'Blackburn is trying to explain a non-fact'.

Shoemaker develops his point as follows:

Much of our practical evaluation of things are of things that are not actual, and we regularly have to compare hypothetical situations with one another and with actual ones. And when it would be absurd to say that one actual $\mathrm{B} *$ situation is morally good and that another is morally bad, it would be equally absurd to say that an actual one is morally good and a merely possible one is bad, or that one possible one is good and another different possible one is bad.... In the case of values B*/A supervenience holds across possible worlds as well as within...; so ... it entails $\mathrm{B} / *$ necessity. Blackburn says ... 'Whereas it seems conceptually ... necessary that if two things share a total basis of natural properties, then they have the same moral properties. 'it does not seem a matter of conceptual ... necessity that any given total natural state of a thing gives it some particular moral property'. But ... what is not conceptually necessary is the conditional 'If $\mathrm{x}$ is $\mathrm{B}$ * then $\mathrm{x}$ is $\mathrm{A}$ '. What is conceptually necessary is not only the intraworld supervenience principle Blackburn has in mind ... but also the 
interworld supervenience principle 'If there is a world $\mathrm{w}$ in which something is B* and $\mathrm{A}$, then in any world $\mathrm{w}^{\prime}$, if something in $\mathrm{w}^{\prime}$ is $\mathrm{B} *$ that thing is $\mathrm{A}^{\prime}$. In virtue of the truth of the latter, the conditional 'if $\mathrm{x}$ is $\mathrm{B}^{*}$ then $\mathrm{x}$ is $\mathrm{A}$ ' will be necessarily true, although not conceptually true if anything in any possible world is B* and A. ... since it is a commonplace that that there are 'metaphysical necessities' that are not conceptual necessities, we should not be surprised to find one here.

Dreir (1992:15) appeals to Hare's example of St Francis of Assisi to argue that we must recognise the interworld supervenience of the moral on the natural:

.... We assume [St Francis] to be a very good man. We know from WS [intraworld supervenience $]^{4}$ that anyone just like Francis in every naturalistic respect is also good. ... What we now want to know is whether any possible person who was just like Francis in every naturalistic respect would be good ... it seems that anyone who denied that would exhibit a linguistic or logical deficiency.

I think all this shows merely that second thoughts are not always better, Blackburn's original formulation does not talk of possible people, situations or worlds or metaphysical necessities (that are not conceptual necessities). So a defender of his challenge can just repeat it in the original terms and demand that the realist explain bare supervenience, so understood, or justify the contention that, as Shoemaker describes the 'ban on mixed worlds', it is also a non-fact.

The defender of early Blackburn need not say any more on the point, I think, but he reasonably can. The reference to (merely) possible people and situations by Blackburn and Dreir should give us pause. It could have been that there was a fat man jammed in the doorway, to use Quine's famous example. Does that mean that there is a possible fat man jammed in the doorway? We do talk of possible Fs, but do we do so in a way that helps us to understand the passages quoted? I could have won the lottery last week. I had a ticket last week (I do not indulge every week). So last week I was a possible lottery winner. But, alas,

\footnotetext{
${ }^{4}$ Dreir distinguishes (where ' $F$ ' ranges over moral properties and ' $G$ ' over natural ones) (WS) 'Necessarily for any F, if Fx then there is a G, Gx and for any y, if Gy then Fy' from interworld supervienience (SS) 'Necessarily for any F, if Fx then there is a G, Gx and necessarily, for any y, if Gy then Fy' where the second 'necessarily' expresses metaphysical necessity.
} 
only a merely possible one. A merely possible lottery winner is not a lottery winner who is possible but not actual, but just an (actual) person who could have been (but wasn't) a lottery winner. One way of understanding talk of possible Fs is as talk of (actual) things that could have been Fs. But can the talk in Dreir of a possible person who was just like St Francis in all naturalistic respects be understood in this way? I could have been a person like St Francis in all naturalistic respects (if we reject the thesis of the necessity of origin, and other controversial theses about identity across worlds which do not seem relevant here). I am therefore a possible person like St Francis in all naturalistic respects, just as last week I was a possible lottery winner. But I am not a good man. Does this refute any thesis of the supervenience of the moral on the natural? No. I am not naturalistically indiscernible from St Francis. It is not clear what other notion of 'a possible person who ...' Drier is using. And it is also not clear whether what Dreir wishes to say is more than that it would not be possible for a person to be naturalistically just like Francis and not be good.

These familiar thoughts might make us hesitate about the distinction between intraworld and interworld supervenience this objection to Blackburn appeals to. In addition, if talk of possible worlds is rejected as merely metaphorical and/or reducible (reasonably enough, following Kripke's (1980) admonitions) the distinction between them must be made (as Dreir does) by the absence/presence of an embedded modal operator.

\section{Intraworld Supervenience}

It is conceptually necessary that, for any $\mathrm{x}$, for any $\mathrm{y}$, if for any natural property $\mathrm{N}, \mathrm{Nx}$ iff $\mathrm{Ny}$, then for any moral property M, Mx iff My

\section{Interworld Supervenience}

It is conceptually necessary that: for any $\mathrm{M}$, if for some $\mathrm{x}, \mathrm{Mx}$ then for some $\mathrm{N}, \mathrm{Nx}$ and it is metaphysically necessary that for any $\mathrm{y}$, if $\mathrm{Ny}$ then My.

But the defender of early Blackburn can say that the latter is problematic in at least two ways: it embeds a metaphysical necessity operator, which makes no sense since talk of metaphysical necessity has point only if there are necessary a posteriori truths - but there aren't; and it involves (second order) quantification into that metaphysical context from without, which also makes no sense. He can call on such authorities as Quine, Dummett and Lewis in support of these claims. Of course, all this can be denied. The point is merely that the appeal to the intraworld/interworld distinction which the standard objection to Blackburn 
makes is not unproblematic. There is a defensible position that the formulation of the supervenience of the moral on the natural as an interworld principle constitutes a confused attempt to capture the conceptual constraint governing moral discourse. ${ }^{5}$

But how then should the supervenience claim, in its full generality, be understood? Lewis has an answer. Everyone's first thought is right. A (moral) properties supervene on B (naturalistic) properties just in call all things alike in B properties are alike in A properties all things. The quantification is unrestricted. ${ }^{6}$

If we accept this Blackburn's 1971 bare conceptual supervenience thesis can be restated without reference to any non-epistemic modality. (i) All things alike in the natural predicates they satisfy are alike in the moral predicates they satisfy, and this is a priori knowable. However, (ii) given any naturalistic predicate, however, complex, and any moral predicate, it is not a priori knowable that if something satisfies the former it satisfies the latter. This is what the realist is challenged to explain.

\section{III}

I turn now to my proposed explanation. I say that it sufficient, but also necessary, for the realist to meet Blackburn's challenge that names of moral properties are Evansian descriptive names (equivalently, rigidified descriptions) part of whose meaning is that they are names of natural properties, and that moral predicates are ones which are a priori equivalent to ones which embed names of moral properties.

\footnotetext{
${ }^{5}$ This is also argued by Miller (2018) appealing to Kant's critique of the ontological argument.
}

${ }^{6}$ See Lewis (1986: 17). Lewis writes: 'The original simple statement of supervenience is the right one, in all cases: there could be no difference of one sort without a difference of the other sort. What got us into trouble was to insist on reading the 'could' as a diamond ... the real effect seems to be to unrestrict quantifiers'. His statement of the general form of a supervenience claim is: 'Among all the worlds, or all the things in all the worlds ... there is no difference of one sort without a difference of the other sort'. The quantification over worlds here is eliminable since every world is in (is a part of) itself. Secondly, Lewis would remove the restriction to things in worlds in giving a fully general statement of a supervenience thesis since he acknowledges the existence of things not in worlds, transworld individuals, with parts in several worlds. 
So I begin with Evans's idea of a descriptive name. Evans introduces 'Julius' as a descriptive name of the inventor of the zip, who, in fact, was Whitcomb L. Judson (WLJ). This is a descriptive name in Evans's sense since a competent user must regard it as a priori that Julius is the inventor. ${ }^{7}$ By contrast 'WLJ' is not a descriptive name, but a natural name since there is no description (other than one embedding that name) which the competent user must a priori associate with it (or so we are told by Kripke). The crucial features of 'Julius' for our purpose is that it is a (de jure) rigid designator of $\mathrm{WLJ}$, but that it is not a priori knowable that Julius=WLJ (since it is a priori that Julius is the inventor but not a priori that WLJ is). Hence, it is not a priori knowable that an acquaintance of WLJ is an acquaintance of Julius, but it is a priori knowable that two people with the same acquaintances (given by a list of natural names) are such that if one of them is an acquaintance of Julius the other is.

Trivially, then, it follows, using the notion of conceptual entailment, that there is no conceptual entailment from satisfying a predicate of the form ' has all and only N1 ... Nn as acquaintances (where the $\mathrm{Ni}$ are all natural names) to satisfying the predicate 'is an acquaintance of Julius'. Although it is knowable a priori, given the meaning of 'Julius' that two people with the same acquaintances must either both or neither be acquaintances of Julius.

Of course, this has the same form as the bare conceptual supervenience thesis with which Blackburn challenges the moral realist. So we have a model form of explanation the moral realist can appeal to.

We can run through the same explanatory story with 'Julius' replaced by the rigidified description 'the actual inventor of the zip'.

Before seeing how the moral realist can use this model to answer Blackburn's challenge we can warm up by considering the case of secondary properties. This application is suggested by Kripke in Naming and Necessity in fn. 71 and the corresponding text, but it is in tension with Kripke's main line of thought which is that names of natural kinds of

\footnotetext{
${ }^{7}$ Hence sentences of the form 'Julius is F' and 'The inventor of the zip is F' have same assertoric content but differ in ingredient sense (Dummett: 1973: 446ff.); one makes the same claim about the world whichever one uses, but because 'Julius' is a name and hence rigid embedding them in modal and counterfactual contexts results in sentences with different assertoric contents.
} 
phenomena as well as names of natural kind of thing and natural kinds of stuff are analogous to natural names of people and other individuals, not to descriptive names and not a priori linked to any description (not embedding the name). But suppose 'heat' is a descriptive name of a secondary property whose a priori reference-fixing description is of the form 'that physical property of physical objects which causes such-and-such a sensation (sensation S) in us'. Then, if ${ }^{8}$ this is so, and this descriptive name denotes, if in fact there is a physical property of physical objects which is the physical property of physical objects which causes this effect in us, and it is in fact the physical property a physical object has when its parts are in motion, what the name names is that property. But there is no a priori knowable route from a thing's being a possessor of the property having its molecules in motion to its being a possessor of the property heat. But it can be ruled out a priori, given that this is what 'heat' means, that physical objects possessing the same physical properties can be such that one is a possessor of the property of heat and the other not. This is because, to repeat, we are assuming that 'heat' means 'the (actual) physical property of physical objects which causes ...', and we are assuming that this description denotes. So if 'is hot' is defined to mean 'is a possessor of the property of heat' it is conceptually ruled out that two physical objects which are possessors of all the same physical properties might differ in that one is hot and the other not. But it is not a priori knowable that if a thing's molecules are in motion it is hot.

Of course, we could understand 'heat' differently. We might simple define it as synonymous with the description which fixes its reference on the proposal just given. Then 'heat' would be a flexible designator and so it would be correct to say that if we were constituted differently, so not sensitive to molecular motion in the way we in fact are, molecular motion would not be heat, but perhaps something else would be. On this understanding the meaning of 'heat' would be response-dependent. But given that we understand 'heat' as a descriptive name, and so as a rigid designator, whose reference is fixed by the description 'the physical property of physical objects which cause in us sensation $S$ ' it would not be correct to say that if we were not sensitive to molecular motion it would not be heat. Rather, it would be correct to say that in such circumstances we would not be sensitive to heat. So if 'heat' is a descriptive name with the meaning suggested its meaning is not response-dependent, but merely response-enabled.

\footnotetext{
${ }^{8}$ I stress that this is a big 'if'. The example is merely hypothetical. I explain in the final section why I do not accept it.
} 
This response-dependent/response-enabled distinction comes from Yablo (2002), elaborated by Dohrn (2018). They illustrate with the example of shapes. Shapes are objects defined by their mathematical description. The circle is the shape defined by the equation of a circle. Suppose we introduce the name 'the oval' as a descriptive name of that shape which causes a certain a certain visual sensation in us - which looks egg-shaped. The name is tied a priori to that description, but it is a rigid designator of the shape, which is defined by a certain complex mathematical description, M. So it is a priori that the oval is the shape instantiations of which look egg-shaped to us. But although the oval is the shape with mathematical description $\mathrm{M}$, there is no conceptual entailment from possessing the shape $\mathrm{M}$ to possessing the shape oval. However, it is knowable a priori that if two objects are identical in shape (as defined by their mathematical description) each possesses the shape, oval, or neither does. Hence, if 'is oval' is a predicate of material objects defined to mean 'is an instance of the oval' it is not conceptually guaranteed that if something is an instance of shape $\mathrm{M}$ it is oval, but it is conceptually guaranteed that if two objects are instances of the same shape (defined mathematically) either is oval if the other is. Again we have a case of bare conceptual supervenience.

Yablo and Dohrn apply their idea to the case of moral predicates in a defence of Humean sentimentalism. We can now see how, using these considerations, a naturalist can respond to Blackburn.

Hume gives two definitions of causation. One as a philosophical relation:

We may define a CAUSE as an object precedent and contiguous to another, and where all the objects resembling the former are plac' $d$ in like relations of precedency and contiguity to those objects that resemble the latter (1978: 170).

And once as a natural relation:

A CAUSE is an object precedent and contiguous to another, and so united with it, that the idea of the one determines the mind to form the idea of the other, and the impression of the one to form a more lively idea of the other (1978: 170).

It seems clear enough what is going on. According to Hume, there are two things to be taken into account in explaining causation. There is, on the one hand, what is going on in the world, independently of its effect on any observer, and there is also, on the other hand, 
what goes on in the mind of a (human) observer (one of us) who is prompted to apply the concept of causation to the world.

The case is parallel, in Hume's view, in the case of moral and aesthetic properties. Here too there is that in the world to which we respond and there is our response, and so a similar dual definition is possible. In fact, Hume offers precisely such a pair of definitions of virtue, or personal merit, in the Enquiry Concerning the Principles of Morals. On the one hand, he says: 'Personal merit consists altogether in the possession of mental qualities, useful or agreeable to the person himself or to others' (1975: 267). On the other hand, he asserts: 'the hypothesis we embrace is plain ... It defines virtue to be whatever mental action or quality gives to a spectator the pleasing sentiment of approbation' (1975: 289).

According to Hume the primary bearers of personal merit or demerit are enduring mental qualities, or traits of character. So virtue is a property of personal qualities; it is a property of properties. So following Hume let us fix the reference of the descriptive name 'virtue' as 'that complex naturalistically specifiable property of all and only those enduring human mental qualities manifestations of which give to a (human) spectator (i.e., to us) ${ }^{9}$ a pleasing sentiment of approbation'. ${ }^{10}$ This property of properties, according to Hume, is the property a mental quality has if and only if it is useful or agreeable to the person himself or to others. But this identity is only a posteriori discoverable. So that a mental quality possesses the property of being useful or agreeable to its possessor or others does not conceptually entail that it possesses the property of virtue. But it is knowable a priori that if two mental properties have all the same naturalistically defined properties, one of these possesses the property of virtue if the other does. All of this follows from the assumption that 'virtue' is a descriptive name of a property of mental qualities, a priori linked to the description 'the complex naturalistically specifiable property of all and only those human mental qualities which give to a spectator (to us) the pleasing sentiment of approbation', and that this description in fact denotes. ${ }^{11}$

\footnotetext{
${ }^{9}$ The first-person (plural) indexical here is essential. See Perry (1979).

${ }^{10}$ Note that this description, though it embeds an indexical, is not a rigid designator.

${ }^{11}$ According to Hume the moral sentiments of approbation and disapprobation are particular pleasures and pains caused by the contemplation of human characters. Not all pleasures and pains are the same. The pleasure arising from the contemplation of virtue is different from
} 
So I propose, Blackburn's challenge to the realist can be met by a Humean sentimentalist.

The above is a way of spelling out the Yablo/Dohrn thought that moral predicates are response-enabled and it is also in line with and spells out Wright's thought in his review of Blackburn's Spreading the World (1985: 316): 'moral qualities admit of an odd kind of variable realization; they are constrained to be whatever natural properties they turn out, a posteriori, to be'. Another anticipation is Noonan's (1987: 84-5) remark:

'One simple-minded form of naturalism is that good (applied to an action, character or person) means 'such as to elicit approval from human beings (or 'from us') and 'bad' means 'such as to elicit disapproval from human beings (us)'. Suppose instead that 'good' means 'possesses a combination of natural properties which in the actual

that arising from contemplation of an inanimate object (a beautiful sunset) (Hume 1978: 471). The pain arising from awareness of the good qualities of an enemy (courage, intelligence etc.,) is not the pain of disapprobation (Hume 1978: 472). The sentiments of approbation and disapprobation are those arising when a 'character is considered in general, without reference to our particular interest'. Approbation and disapprobation are also distinguished from other pleasures and pains by the fact that they invariable lead to pride and humility (in ourselves) and love and hatred (towards others). They are caused by the contemplation of character traits by the mechanism of sympathy. Virtuous traits produce pleasurable feelings in their possessors or other in their circle (either mediately or through their utility). Observers are infected (as we may be infected by disease) via sympathy by these pleasurable feelings and thus approve of the virtuous traits. Sympathy is a mechanism which converts ideas into impressions and hence the ideas of the passions of others' passions into passions. I become aware of someone's grief from his behaviour and thus arrive at the idea of (and belief in) that emotion. This is then converted into an impression and 'acquires such a degree of force and vivacity to become itself a passion' (Hume 1978: 317). This is because our impression of ourselves has an unparalleled degree of vivacity and is 'always intimately present with us... Whatever object, therefore, is related to ourselves must be conceived with a like vivacity of conception'. However, if one does not like this Humean story (how could one not?), for our purposes it does not matter. Blackburn himself, as an expressivist, needs accounts of approbation and as non-cognitive attitudes. So the realist can just borrow them to meet his challenge. 
world elicits approval from human beings (us)'. .... Then the moral will be barely supervenient $_{\mathrm{c}}$ [conceptually supervenient] on the natural. ${ }^{12}$

One final point to close this section. The fact that 'virtue' has been defined as a descriptive name, hence a rigid designator, should not be overemphasized. That it is so defined has no role in the explanation given of the bare conceptual supervenience of the moral on the natural which is Blackburn's explanandum - obviously, since it is only bare conceptual supervenience. ${ }^{13}$ So why was it so defined? Simply because 'virtue' (like 'the oval' and 'heat') is a rigid designator. ${ }^{14}$ This is just a fact of language, just as it is a fact that 'Aristotle' is a rigid designator. So if the suggested account is correct, its meaning is indeed

${ }^{12}$ Other anticipations are Davies and Humberstone's (1980) discussion of Evan's work where the possibility that moral predicates are descriptive names is sketched, but without reference to Blackburn's challenge and Dreir (2000) where in Section III C the possibility that moral terms and also names of natural kinds are rigidified descriptions is sketched as a way the nonreductive naturalist can respond to Blackburn, but without distinguishing the cases (as is argued in Section IV below must be done), and without specifying the reference-fixing description which stands to 'goodness' as 'the transparent, potable liquid found in our seas and rivers' stands to 'water' (according to Kripke and Putnam). Dreir's main proposal is that moral predicates be thought of as having an indexical component; this is along the lines of Noonan's (1987) suggestion and the present one.

${ }^{13}$ It is not a priori that being an acquaintance of WLJ entails being an acquaintance of the inventor of the zip, but if two people have the same acquaintances, one is an acquaintance of the inventor of the zip if the other is.

${ }^{14}$ Of course, given that 'Julius' is rigid we can also say that if Tom is in fact acquainted with Julius then if Dick had had the same acquaintances as Tom in fact has, Dick would have been acquainted with Julius. Likewise, given that 'virtue' is rigid we can say that since St Francis was virtuous if someone had had (counterfactually) all the natural qualities St Francis had (historically) he would also have been virtuous. It is the truth of this counterfactual which is the datum that convinces philosophers that interworld supervenience must be the explanandum in Blackburn's challenge. But one can accept the datum whilst rejecting interworld supervenience, or even the intelligibility of its statement. 
response-enabled but not response-dependent one. Morality is objective (given the rigidity), ${ }^{15}$ but contextual (due to the indexicality of the defining reference-fixing description). ${ }^{16}$

${ }^{15}$ Since, for example, 'eating fish is wrong (the manifestation of a vicious character)' and 'eating fish has a naturalistically specifiable characteristic which causes disapproval in us', like 'Julius is rich' and 'the inventor of the zip is rich', differ in ingredient sense; they yield different results in modal and counterfactual contexts. So if eating fish is wrong it would still have been wrong if we had been differently psychologically constituted and approved of it. However, the sentences have the same assertoric content. So, if I sincerely assert the first you can correctly state, 'He believes that eating fish has (some or other) natural characteristic which causes disapproval in himself and his circle'. My belief is a belief about me, but also others and features of the world.

${ }^{16}$ A challenge for such an account is to explain what appear to be genuine disagreements between two speakers affirming and denying a moral assertion. This lies off our track, but I will say a little. It is important that the reference-fixing description contains the first-person plural pronoun. The reference of the first-person singular pronoun is automatically secured as the speaker, but this not so for the plural form. So you and I can make the same reference using 'we/us'. This is similar to the case with 'here'. It is tempting to say that 'here' means: where I am. But there is no one place where I am, so two people can refer to the same place using 'here'. Hence there can be genuine disagreement if one says 'It is F here' and the other says 'It is not F here' (e.g., if they have just checked into a hotel and are discussing whether 'Breakfast is served here from 6.00a.m.'). But there need not be genuine disagreement (if, for example, they are talking on the phone across different continents and one says 'It is hot here' and the other says, 'It is not hot here'). The same is true on the account suggested for one person's utterance of the form ' $\mathrm{X}$-ing is wrong' and another's of the form ' $\mathrm{X}$-ing is not wrong'. If I am discussing vegetarianism with my daughter and she says, 'Eating fish is wrong' and I say 'Eating fish is not wrong' there may be genuine disagreement (because our uses of the first-person plural would have a common reference). But perhaps there will not be if I am in conversation with a reincarnated mediaeval Samurai (who has been given a fast course in English) and I say, 'Honour killing is wrong' and he says, 'Honour killing is not wrong'. 
In this final section I want to respond to a worry and then conclude.

The worry is that the account given is too good. We can equally well, using the procedure sketched, explain the bare conceptual supervenience of the mental on the physical, or of our layman's classificatory scheme of manifest kinds on the chemical. But in these cases there is not bare conceptual supervenience. Hence the procedure must be flawed since it can be used to 'explain' non-facts.

The mental is not conceptually supervenient on the physical. Someone, call him Descartes, who does not rule out the possibility of a mental difference between physically indiscernible things may be old-fashioned and wrong, but he does not thereby prove himself to be incompetent in the use of mental vocabulary. But if 'pain', say, can be defined as a descriptive name with its reference fixed as 'that physical property of individuals which ...' then he is. But the answer, of course, is that 'pain' cannot be so defined - as shown by the fact that Descartes' use of mental vocabulary does not display conceptual incompetence.

Again, it is surely correct that what manifest kind something belongs to - water, gold etc., - is not conceptually supervenient on its chemical characterization. It does not display incompetence in the use of this vocabulary if one allows that possibility that things might differ in manifest kind at the macroscopic level though chemically indistinguishable (indistinguishable at the level of chemical description). But again all this shows is that 'water', say, is not a descriptive name coreferential with the description 'the chemical kind whose instances fill our seas, rivers etc.,' . It is not even the case, I would say, that it displays incompetence in the use of everyday vocabulary for manifest kinds if one allows the possibility that two samples of stuff which are macroscopically manifestly different cannot be told apart in any microscopic terms. The same is true of secondary quality terms (hence why I said previously that I consider the proposal that they are descriptive names of physical properties of objects merely hypothetical). Consider the supposition that there is a substance as sweet as sugar which is found, by giving minute samples to human tasters, to be a mixture of two types of substance, one twice as sweet as sugar, the other tasteless. However, no way can be found to identify the type of a sample without appeal to human tasters, and this inability is absolute - nothing ever could be done to distinguish the types expect by the involvement of human tasters. Someone who entertains this supposition is profoundly at odds with our modern Western world view, but I do not think that entertaining it proves a failure to grasp the very meaning of 'sweet'. Hence names of secondary qualities are not descriptive 
names of microscopically specifiable physical features of objects and it is not a conceptual truth that secondary qualities are supervenient on microscopically identifiable physical properties.

But the case of moral terms is very different. The supposition that two people might in all naturalistic respects be indistinguishable yet one be evil and the other good is one we can simply do nothing with. Someone who makes it does reveal himself to be incompetent in the use of moral terms. So to accept the proposed account of the meanings of moral terms as descriptive names of natural properties does not commit one to making analogous claims about terms for secondary qualities, manifest kinds or mental properties. The moral realist can distinguish this case from the others.

Conclusion; the datum which Blackburn identifies is one that can be specified without appeal to anything other than epistemic modality: it is a priori knowable that there is no moral difference without a natural difference but there is no a priori knowable route from satisfaction of any naturalistic predicate to satisfaction of a moral predicate. The first half of this claim can be called the thesis of the ascriptive supervenience of the moral on the natural (Klagge 1988). It embodies a constraint of conceptual competence on the user of moral predicates. The problem for the realist is to retain his basic semantic claim, qua realist, that moral predicates refer to moral properties, whilst accommodating the fact of ascriptive supervenience of the moral on the natural along with the lack of conceptual entailment from (an a priori route from) naturalistic predicates to moral predicates. That requires a semantic link between moral predicates and natural ones. My suggestion is that by regarding the meaning of moral predicates as derivative from the meaning of moral terms, and regarding the latter as descriptive names whose references are fixed by descriptions whose meanings include that they are descriptions of natural properties this semantic link is secured. Specifically, on the Humean sentimentalist proposal sketched 'is a virtuous mental quality' means 'is a mental quality possessing virtue' and 'virtue' is a descriptive name of the secondlevel natural property possessed by a mental quality which gives to a spectator (one of us) the pleasing sentiment of approbation. But this as a matter of empirical fact is the natural property of being useful or agreeable to its possessor or others. So the moral is barely conceptually supervenient on the natural and Blackburn's challenge to the realist answered.

\section{References}


Blackburn, S. 1970/1993, “Moral Realism”, in: Essays in Quasi-Realism, Oxford: Oxford University Press, 111-129.

Blackburn, S. 1984, Spreading the Word, Oxford: Clarendon Press.

Blackburn, S. 1985/1993, “Supervenience Revisited”, in: Essays in Quasi-Realism, Oxford: Oxford University Press, 130-148.

Bloomfield, P. 2001, Moral Reality, Oxford: Oxford University Press.

Davies, M. and Humberstone, L. 1980 Two Notions of Necessity, Philosphical Studies, 38: $1-30$

Dohrn, D. 2018 “Moral Sentimentalism in Counterfactual Contexts: Moral Properties Are Response-Enabled”. Philosophia, 46:69-82

Dreier, J. 1992, “The Supervenience Argument Against Moral Realism”, Southern Journal of Philosophy, XXX, 3: 13-38.

Dummett, M.A.E 1973 Frege: Philosophy of Language, London: Duckworth.

Evans, M.G.J. 1979, “Reference and Contingency”, The Monist, 62: 161-89.

Hume, D. 1975, Enquiries Concerning Human Understanding and Concerning the Principles of Morals, ed. L.A. Selby-Bigge and P.H. Nidditch, Oxford: Oxford University Press, $3^{\text {rd }}$ edn. Hume, D. 1978, A Treatise of Human Nature, ed. L.A. Selby-Bigge and P.H. Nidditch, Oxford: Oxford University Press, $2^{\text {nd }}$ edn.

Klagge, J. 1984, “An Alleged Difficulty Concerning Moral Properties”, Mind, 93: 370-380.

Klagge, J. 1988, “Supervenience: Ontological and Ascriptive”, Australasian Journal of Philosophy, 66: 461-469.

Lewis, D 1986, On the Plurality of Worlds, Oxford: Blackwell.

Majors, B. 2009, “The Natural and the Normative", Oxford Studies in Metaethics, 4: 29-52.

McFetridge, I. 1985, "Supervenience, Realism, Necessity”, The Philosophical Quarterly, 35: $245-258$.

Mcpherson, T. 2012, "Ethical Non-Naturalism and the Metaphysics of Supervenience”, in Oxford Studies in Metaethics, 7: 205-234. 
Miller, A. 2018, “”Moral Supervenience: A defence of Blackburn's argument”, Dialectica, 71 (4): 581-601

Moore, G. E. 1903, Principia Ethica, Cambridge: Cambridge University Press.

Moyer, M. 2008, "Weak and Global Supervenience Are Strong”, Philosophical Studies, 138: $125-150$.

Noonan, H. 1987, “Supervenience”, The Philosophical Quarterly, 37: 78-85.

Perry, J. 1979, “The Problem of the Essential Indexical”, Noûs, 13: 3-21.

Shoemaker, S. 1987, “Review of Blackburn's Spreading The Word”, Noûs, 21: 438-442.

Sobel, J. 2001, "Blackburn's Problem: On its Not Insignificant Residue", Philosophy and Phenomenological Research, LXII: 361-383.

Wright, C. 1985 "Review of Blackburn Spreading the Word” Mind, 94: 310-19

Yablo, S. 2002. "Coulda, Woulda, Shoulda" in T. S. Gendler \& J. Hawthorne (Eds.), Conceivability and Possibility, 441-492. Oxford: Clarendon Press.

Zangwill, N. 1995, "Moral Supervenience”, Midwest Studies in Philosophy, 20: 240-262. 